\title{
Propensity score-matched comparison of stenting as a bridge to surgery and emergency surgery for acute malignant left-sided colonic obstruction
}

Yuepeng $\mathrm{CaO}^{1,2 \dagger}{ }^{\dagger}$, Qing Chen ${ }^{3 \dagger}$, Zhizhan $\mathrm{Ni}^{1 \dagger}$, Feng Wu ${ }^{1,4}$, Chenshen Huang ${ }^{1}$, Jinzhe Zhou ${ }^{1}$, Songze Zhang ${ }^{1}$, Bujun $\mathrm{Ge}^{1^{*}}$ and Qi Huang ${ }^{1^{*}}$

\begin{abstract}
Background: Bridge to elective surgery (BTS) using self-expanding metal stents (SEMSs) is a common alternative to emergency surgery (ES) for acute malignant left-sided colonic obstruction (AMLCO). However, studies regarding the long-term impact of BTS are limited and have reported unclear results.

Methods: A multicenter observational study was performed at three hospitals from April 2012 to December 2019. Propensity score matching (PSM) was introduced to minimize selection bias. The primary endpoint was overall survival. The secondary endpoints included surgical approaches, primary resection types, total stent-related adverse effects (AEs), surgical AEs, length of hospital stay, 30-day mortality and tumor recurrence.

Results: Forty-nine patients in both the BTS and ES groups were matched. Patients in the BTS group more often underwent laparoscopic resection [31 (63.3\%) vs. 8 (16.3\%), $\mathrm{p}<0.001$ ], were less likely to have a primary stoma [13 (26.5\%) vs. 26 (53.1\%), $p=0.007$ ] and more often had perineural invasion [25 (51.0\%) vs. $13(26.5 \%), p=0.013]$. The median overall survival was significantly lower in patients with stent insertion ( $41 \mathrm{vs.} 65$ months, $p=0.041$ ). The 3-year overall survival ( 53.0 vs. $77.2 \%, p=0.039$ ) and 5 -year overall survival (30.6 vs. $55.0 \%, p=0.025)$ were significantly less favorable in the BTS group. In multivariate Cox regression analysis, stenting (hazard ratio $(H R)=2.309(1.052-5.066)$, $p=0.037)$, surgical AEs $(H R=1.394(1.053-1.845), p=0.020)$ and pTNM stage $(H R=1.706(1.116-2.607), p=0.014)$ were positively correlated with overall survival in matched patients.

Conclusions: Self-expanding metal stents as "a bridge to surgery" are associated with more perineural invasion, a higher recurrence rate and worse overall survival in patients with acute malignant left-sided colonic obstruction compared with emergency surgery.
\end{abstract}

Keywords: Acute malignant left-sided colonic obstruction, Self-expanding metallic stent, Propensity score matching, Overall survival

*Correspondence: bujun_ge@163.com; hqhq007@hotmail.com

${ }^{\dagger}$ YuepengCao, Qing Chen and Zhizhan Ni contributed equally to this work

1 Department of General Surgery, Tongji Hospital, Tongji University School of Medicine, 389 Xincun Road, 200065 Shanghai, China

Full list of author information is available at the end of the article

\section{Background}

Colorectal cancer (CRC) is the third most commonly diagnosed cancer and accounts for approximately $10 \%$ of cancer-related deaths worldwide [1]. A total of 7-29\% of CRC patients present with acute large bowel obstruction [2]. These patients are mainly in advanced disease stages

(c) The Author(s) 2021. This article is licensed under a Creative Commons Attribution 4.0 International License, which permits use, sharing, adaptation, distribution and reproduction in any medium or format, as long as you give appropriate credit to the original author(s) and the source, provide a link to the Creative Commons licence, and indicate if changes were made. The images or other third party material in this article are included in the article's Creative Commons licence, unless indicated otherwise in a credit line to the material. If material is not included in the article's Creative Commons licence and your intended use is not permitted by statutory regulation or exceeds the permitted use, you will need to obtain permission directly from the copyright holder. To view a copy of this licence, visit http://creativecommons.org/licenses/by/4.0/. The Creative Commons Public Domain Dedication waiver (http://creativecommons.org/publicdomain/zero/1.0/) applies to the data made available in this article, unless otherwise stated in a credit line to the data. 
and exhibit poor clinical conditions, and most of them need urgent surgical interventions [3]. In addition to the high morbidity and mortality rates of acute malignant colonic obstruction (AMCO) itself in the emergency setting, conventional emergency surgery (ES) is frequently followed by severe complications, such as anastomotic leakage and surgical site infection [4,5]. Moreover, ES is accompanied by a high risk of stoma creation, which often becomes permanent [6].

In the $1900 \mathrm{~s}$, self-expanding metal stents (SEMSs) were first utilized in the treatment of palliative malignant rectal obstruction [7]. Since then, SEMSs have been increasingly used as an alternative option for AMCO treatment either as palliation or as a bridge to surgery (BTS). BTS provides a period of "optimization" of the patients' clinical condition, allowing adequate oncological staging, accurate anesthetic assessment, optimal colonic preparation and early peri-operational chemotherapy [2, 5]. Therefore, decompression by SEMS insertion can transform the ES into an elective procedure, leading to subsequent medical stabilization and an increased rate of primary anastomosis. SEMS seems to be an effective and safe technique, and the benefits of short-term outcomes have been confirmed by recent meta-analyses compared to ES [8-10]. However, SEMS as BTS is associated with annoying stent-related complications, including perforation, stent migration and reobstruction [6, 11]. In addition, BTS has the potential risk of tumor cell dissemination after stent insertion, leading to worse oncologic outcomes $[12,13]$. Moreover, randomized controlled trials (RCTs) and related meta-analyses comparing BTS and ES are limited to specific populations and provide inconsistent results on surgical and oncological outcomes. Most studies evaluating the outcomes of BTS are conducted at single centers, and optimal matching is often lacking $[2,5,14]$. The objective of this study was to compare the surgical and oncological outcomes of BTS and ES in the management of AMLCO using propensity score-matched (PSM) analysis.

\section{Methods}

We performed a retrospective observational study of patients with AMLCO treated with curative intent, in three hospitals (Shanghai Tongji Hospital, Shanghai, China; Ningbo First Hospital, Ningbo, China; Ningbo Second Hospital, Ningbo, China) from April 2012 to December 2019. All patients who underwent resection for AMLCO were identified from in-hospital medical records. Data on baseline characteristics and short-term surgical outcomes were collected from medical records. Data on long-term oncological outcomes were collected upon follow-up treatment or survey. This study was approved by the institutional review board of Shanghai
Tongji Hospital, Ningbo First Hospital and Ningbo Second Hospital.

\section{Patient selection}

Patients were considered to have acute colonic obstruction based on clinical signs of colonic obstruction (abdominal distention, constipation and vomiting) and related radiological signs under computed tomography $(\mathrm{CT})$ scan. Patients were then separated into 2 distinct groups based on the type of procedure performed. The BTS group included patients who underwent SEMS placement followed by scheduled elective surgery, and the ES group included patients who were treated with emergency surgery. Patients undergoing SEMS placement or ES as palliative treatment were excluded. Patients who were lost to follow-up were also excluded from the analysis. Patients who failed SEMS insertion procedure and underwent emergency surgery were classified in the BTS group according to the intention-totreat concept.

The required sample size in each group was calculated using G*Power (Universitat Kiel, Germany) software. The primary endpoint of the present study was 5 year overall survival (OS). Previous studies reported that the 5-year OS after emergency surgery for acute malignant left-sided colonic obstruction was $40-80 \%(1,2)$. We assumed the 5 year OS to be $60 \%$ based on previous studies and our clinical experience. However, compared to ES, the 5 year OS was difficult to calculate because studies on long-term outcomes were lacking. The difference in 5-year OS between BTS and OS was reported to be $42-60 \%(3,4)$. Therefore, we assumed a $50 \%$ difference in 5 -year OS for the 2 groups (BTS vs. ER 30 vs. 60\%). A minimum sample size of 42 patients per group was estimated to obtain a power of $80 \%$ for detecting a difference at the $5 \%$ level. In our study, a total of 49 patients per group was included, with a G-power of $85.8 \%$.

\section{Data recording and follow-up}

Patient baseline characteristics (age, sex, ASA score, comorbidities, tumor location and clinical TNM stage) and perioperational characteristics (surgical approach, operation method, total hospital stay, stent-related adverse effects (AEs), surgical AEs and adjuvant chemotherapy) were collected from medical records. The metastasis found within 90 days after surgery was defined as pM1. Follow-up data, including tumor recurrence and overall survival, were obtained during routine clinical care and telephone contact with the patient.

\section{Stent placement and surgery}

The colonic stents used in this study were uncovered and inserted with direct endoscopic visualization. All 
procedures were performed under general anesthesia. Stent placement was performed following standard protocols as previously described [15]. A guidewire was introduced across the stenosis and beyond the obstruction, and the stent was deployed over the guidewire. Correct positioning of the stent was confirmed by fluoroscopy.

Elective surgery was performed at a median of 11.5 days after stent insertion. All patients underwent standard colectomy and regional lymphadenectomy. The surgical approaches, operation methods and the range of resection were determined by the surgeon based on the tumor location, tumor stage and the patients' general condition.

\section{Endpoints}

The technical success of SEMS placement was defined by successful stent placement and the ability to pass stool. Clinical success was defined as relief of obstructive symptoms within $48 \mathrm{~h}$ of SEMS placement or ES. Stoma creation included temporary stoma with return after initial decompression surgery and permanent stoma according to the patient's general condition, cancer progression and patient's choice. The primary endpoint for this study was overall survival (OS). The secondary endpoints included surgical approach, primary resection type, total stent-related AEs (tumor perforation, bleeding and reobstruction), surgical AEs (wound infection, anastomosis leakage), length of hospital stay, 30-day mortality and tumor recurrence. Surgical AEs were classified according to the Clavien-Dindo classification [16].

\section{Statistical analysis}

Propensity score matching (PSM) is used for best possible matching when randomized control trial (RCT) studies are not possible or not available. PSM represents the probability of receiving treatment A rather than B for a patient with given observed baseline characteristics with a summary score, the propensity score. The variables selected in PSM analysis included age, sex, ASA score, comorbidities, tumor location and clinical TNM (cTNM) stage. These variables were selected since they could affect the oncological outcomes of ACMO. PSM analysis was performed using a logistic regression model. This one-to-one matching was performed by using a caliper width that was 0.2 of the standard deviation of the log of the propensity score.

Data were analyzed using SPSS 22.0 (Chicago, IL, USA). Categorical variables were analyzed using the $\chi^{2}$ test or Fisher's exact test. Continuous data were analyzed using Student' s t test and presented as the means \pm standard deviation. Overall survival was defined as the time between diagnosis and the time of death or last follow-up. Survival curves were generated using the adjusted Kaplan-Meier method [17] and compared using a $\log$-rank test. A $\mathrm{p}<0.05$ was considered statistically significant.

\section{Results \\ Baseline characteristics}

From April 2012 to December 2019, we retrospectively identified 287 patients who were admitted for AMLCO in three hospitals. Patient selection is shown in Fig. 1. After exclusion of patients with palliative operation $(n=79)$ and patients with failed follow-up $(n=38)$, a total of 167 patients who received either SEMS as BTS $(\mathrm{n}=49)$ or ES $(\mathrm{n}=118)$ were included in the analysis. Using 1:1 propensity score matching, 49 patients in the ES group were matched to 49 in the SEMS group.

Before matching, baseline characteristics were comparable between the BTS and ES groups with the exception that more patients had coronary artery disease in the SEMS group (9 of 49 in the SEMS group (18.4\%) and 10 of 118 in the ES group (8.5\%)) (Table 1). After propensity matching, no significant difference was found between the BTS and ES groups regarding sex (36 male patients [73.5\%] in the BTS group and 37 [75.5\%] in the ES group, $\mathrm{p}=0.817$ ), age (mean [SD] age, 68.8 [11.1] years in the BTS group and 68.8 [13.8] years in the ES group, $\mathrm{p}=0.872)$, age range $(\mathrm{p}=0.757)$, ASA score

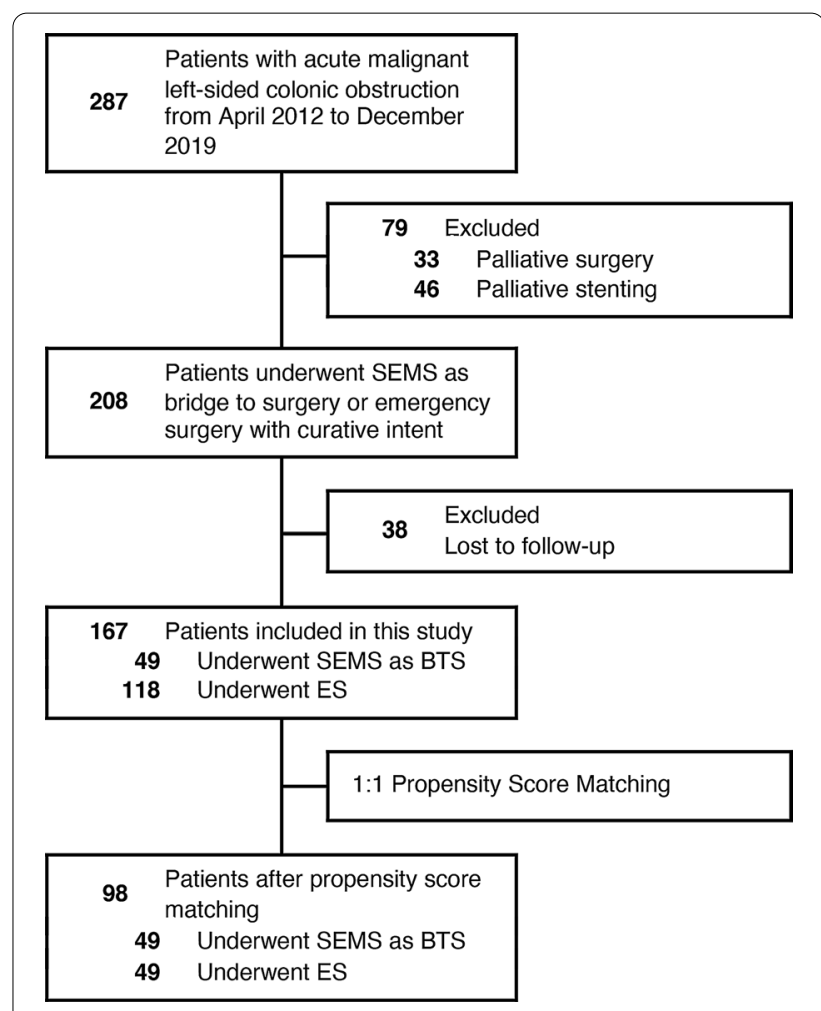

Fig. 1 Flowchart of patient selection 
Table 1 Baseline characteristics

\begin{tabular}{|c|c|c|c|c|c|c|}
\hline & \multicolumn{3}{|c|}{ Before propensity score matching } & \multicolumn{3}{|c|}{ After propensity score matching(1:1) } \\
\hline & BTS $(n=49)$ & $\mathrm{ES}(\mathrm{n}=118)$ & $P$ & BTS $(n=49)$ & $E S(n=49)$ & $P$ \\
\hline Sex & & & 0.152 & & & 0.817 \\
\hline Male & $36(73.5 \%)$ & $73(61.9 \%)$ & & $36(73.5 \%)$ & $37(75.5 \%)$ & \\
\hline Female & $13(26.5 \%)$ & $45(38.1 \%)$ & & $13(26.5 \%)$ & $12(24.5 \%)$ & \\
\hline Age(mean(SD),y) & $68.8(11.1)$ & $68.3(12.6)$ & 0.811 & $68.8(11.1)$ & $68.8(13.8)$ & 0.872 \\
\hline Age range $(y)$ & & & 0.843 & & & 0.757 \\
\hline $25-59$ & $10(20.4 \%)$ & $26(22.0 \%)$ & & $10(20.4 \%)$ & $13(26.5 \%)$ & \\
\hline $60-69$ & $18(36.7 \%)$ & $36(30.5 \%)$ & & $18(36.7 \%)$ & $15(30.6 \%)$ & \\
\hline $70-79$ & $10(20.4 \%)$ & $29(24.6 \%)$ & & $10(20.4 \%)$ & $10(20.4 \%)$ & \\
\hline $80-95$ & $11(22.4 \%)$ & $27(22.9 \%)$ & & $11(22.4 \%)$ & $11(22.4 \%)$ & \\
\hline ASA score & & & 0.348 & & & 0.399 \\
\hline 1 & $6(12.2 \%)$ & $28(23.7 \%)$ & & $6(12.2 \%)$ & $13(26.5 \%)$ & \\
\hline$\|$ & $23(46.9 \%)$ & 48 (40.7\%) & & $23(46.9 \%)$ & $16(32.7 \%)$ & \\
\hline III & $17(34.7 \%)$ & 40 (33.9\%) & & $17(34.7 \%)$ & $18(36.7 \%)$ & \\
\hline IV & $3(6.1 \%)$ & $2(1.7 \%)$ & & $3(6.1 \%)$ & $2(4.1 \%)$ & \\
\hline \multicolumn{7}{|l|}{ Comorbidities } \\
\hline CAD & $9(18.4 \%)$ & $10(8.5 \%)$ & 0.007 & $9(18.4 \%)$ & $6(12.2 \%)$ & 0.400 \\
\hline Hypertension & $18(36.7 \%)$ & $43(36.4 \%)$ & 0.133 & $18(36.7 \%)$ & $17(34.7 \%)$ & 0.833 \\
\hline Diabetes & $3(6.1 \%)$ & $18(15.3 \%)$ & 0.333 & $3(6.1 \%)$ & $5(10.2 \%)$ & 0.461 \\
\hline CPD & $4(8.2 \%)$ & $6(5.1 \%)$ & 0.181 & $4(8.2 \%)$ & $4(8.2 \%)$ & 1.000 \\
\hline Renal dysfunction & $2(4.1 \%)$ & $5(4.2 \%)$ & 0.705 & $2(4.1 \%)$ & $3(6.1 \%)$ & 0.646 \\
\hline Biliary diseases & $6(12.2 \%)$ & $14(11.9 \%)$ & 0.412 & $6(12.2 \%)$ & $5(10.2 \%)$ & 0.749 \\
\hline CVD & $2(4.1 \%)$ & $6(5.1 \%)$ & 0.873 & $2(4.1 \%)$ & $3(6.1 \%)$ & 0.646 \\
\hline Tumor location & & & 0.086 & & & 0.243 \\
\hline Splenic flexure & $8(16.3 \%)$ & $10(8.5 \%)$ & & $8(16.3 \%)$ & $5(10.2 \%)$ & \\
\hline Descending colon & $6(12.2 \%)$ & $30(25.4 \%)$ & & $6(12.2 \%)$ & $12(24.5 \%)$ & \\
\hline Sigmoid colon & $35(71.4 \%)$ & $78(66.1 \%)$ & & $35(71.4 \%)$ & $32(65.3 \%)$ & \\
\hline cTNM stage & & & 0.630 & & & 0.560 \\
\hline$|-|||$ & $47(95.9 \%)$ & $111(94.1 \%)$ & & $47(95.9 \%)$ & $48(98.0 \%)$ & \\
\hline IV & 2 (4.1\%) & $7(5.9 \%)$ & & 2 (4.1\%) & $1(2.0 \%)$ & \\
\hline
\end{tabular}

$C A D$ coronary artery disease, $C P D$ chronic pulmonary disease, $C V D$ cerebrovascular disease

Data are presented as the number (percentage) of patients unless otherwise indicated

$(\mathrm{p}=0.399)$, comorbidities, tumor location $(\mathrm{p}=0.243)$ or clinical TNM (cTNM) stage (2 patients (4.1\%) with stage IV CRCs in the BTS group and 1 (2.0\%) in the ES group, $\mathrm{p}=0.560)$.

\section{Procedure-related characteristics and perioperational outcomes}

SEMS insertion was attempted in 49 patients and was successful in 44 patients with a technical success rate of $89.8 \%$. The technique failure in 5 patients was attributed to a complete colonic obstruction, leading to unsuccessful stent insertions. Stent-related colonic perforation occurred in 2 of 44 patients within $24 \mathrm{~h}$ after stent insertion with a clinical success rate of $85.7 \%$. These 7 patients underwent emergency open surgery for tumor resection.
Table 2 summarizes the procedure-related characteristics and perioperational outcomes. The median interval between SEMS and resection was 11 days (IQR, 7-19 days). After PSM matching, patients in the BTS group more often underwent laparoscopic resection $[31(63.3 \%)$ in the BTS group and $8(16.3 \%)$ in the ES group, $\mathrm{p}<0.001]$, were less likely to have a primary stoma [13 (26.5\%) in the BTS group and 26 (53.1\%) in the ES group, $\mathrm{p}=0.007$, had a higher total in-hospital cost $(78.0 \pm 30.3$ thousand yuan in the BTS group and $62.2 \pm 46.1$ thousand yuan in the ES group, $\mathrm{p}=0.049)$ and more often had perineural invasion [25 (51.0\%) in the BTS group and $13(26.5 \%)$ in the ES group, $\mathrm{p}=0.013]$. Other perioperational outcomes, including surgical adverse effects (Clavien-Dindo classification) 
Table 2 Clinicopathological characteristics

\begin{tabular}{|c|c|c|c|c|c|c|}
\hline & \multicolumn{3}{|c|}{ Before propensity score matching } & \multicolumn{3}{|c|}{ After propensity score matching $(1: 1)$} \\
\hline & BTS $(n=49)$ & $E S(n=118)$ & $P$ & BTS $(n=49)$ & $E S(n=49)$ & P \\
\hline Surgical approach & & & 0.000 & & & 0.000 \\
\hline Laparotomy & $18(36.7 \%)$ & $79(66.9 \%)$ & & $18(36.7 \%)$ & $41(83.7 \%)$ & \\
\hline Laparoscopy & $31(63.3 \%)$ & $39(33.1 \%)$ & & $31(63.3 \%)$ & $8(16.3 \%)$ & \\
\hline Primary resection type & & & 0.068 & & & 0.007 \\
\hline Without stoma & $36(73.5 \%)$ & $69(58.5 \%)$ & & $36(73.5 \%)$ & $23(46.9 \%)$ & \\
\hline With stoma & $13(26.5 \%)$ & $49(41.5 \%)$ & & $13(26.5 \%)$ & $26(53.1 \%)$ & \\
\hline \multicolumn{7}{|l|}{ Stent procedure } \\
\hline Technique failure & $5(10.2 \%)$ & & & $5(10.2 \%)$ & & \\
\hline Stent-related perforations & $2(4.1 \%)$ & & & $2(4.1 \%)$ & & \\
\hline Clinical success & $42(85.7 \%)$ & & & $42(85.7 \%)$ & & \\
\hline Surgical AEs (Clavien-Dindo classification) & & & 0.447 & & & 0.416 \\
\hline 1 & 0 & 0 & & 0 & 0 & \\
\hline 2 & $2(4.1 \%)$ & $11(9.3 \%)$ & & $2(4.1 \%)$ & $8(16.3 \%)$ & \\
\hline 3 & $8(16.3 \%)$ & $3(2.5 \%)$ & & $8(16.3 \%)$ & 0 & \\
\hline 4 & 0 & $2(1.7 \%)$ & & 0 & $1(2.0 \%)$ & \\
\hline 5 & $1(2.0 \%)$ & $5(4.2 \%)$ & & $1(2.0 \%)$ & 0 & \\
\hline pT stage & & & 0.136 & & & 0.301 \\
\hline $\mathrm{T} 1$ & $1(2.0 \%)$ & $2(1.7 \%)$ & & $1(2.0 \%)$ & $2(4.1 \%)$ & \\
\hline $\mathrm{T} 2$ & $1(2.0 \%)$ & $2(1.7 \%)$ & & $1(2.0 \%)$ & $1(2.0 \%)$ & \\
\hline T3 & $19(38.8 \%)$ & $52(44.1 \%)$ & & $19(38.8 \%)$ & $23(46.9 \%)$ & \\
\hline $\mathrm{T} 4$ & $28(57.1 \%)$ & $62(52.5 \%)$ & & $28(57.1 \%)$ & $23(46.9 \%)$ & \\
\hline pN stage & & & 0.655 & & & 0.639 \\
\hline No & $25(51.0 \%)$ & $69(58.5 \%)$ & & $25(51.0 \%)$ & $25(51.0 \%)$ & \\
\hline N1 & $19(38.8 \%)$ & $26(22.0 \%)$ & & $19(38.8 \%)$ & $14(28.6 \%)$ & \\
\hline $\mathrm{N} 2$ & $5(10.2 \%)$ & $23(19.5 \%)$ & & $5(10.2 \%)$ & $10(20.4 \%)$ & \\
\hline pM stage & & & 0.898 & & & 1.000 \\
\hline MO & $41(83.7 \%)$ & $98(83.1 \%)$ & & $41(83.7 \%)$ & $41(83.7 \%)$ & \\
\hline M1 & $8(16.3 \%)$ & $20(16.9 \%)$ & & $8(16.3 \%)$ & $8(16.3 \%)$ & \\
\hline Vascular invasion & $15(30.6 \%)$ & $50(42.4 \%)$ & 0.681 & $15(30.6 \%)$ & $18(36.7 \%)$ & 0.521 \\
\hline Perineural invasion & 25 (51\%) & $40(33.9 \%)$ & 0.039 & $25(51.0 \%)$ & $13(26.5 \%)$ & 0.013 \\
\hline Adjuvant therapy & $26(53.1 \%)$ & $56(47.5 \%)$ & 0.510 & $26(53.1 \%)$ & $25(51.0 \%)$ & 0.686 \\
\hline Total hospital stay (mean(SD), d) & $27.2(15.9)$ & $24.7(14.5)$ & 0.353 & $27.2(15.9)$ & $24.1(13.8)$ & 0.321 \\
\hline Total in-hospital cost(mean(SD), $10^{3}$ RMB yuan) & $78.0(30.3)$ & $61.2(40.7)$ & 0.004 & $78.0(30.3)$ & $62.2(46.1)$ & 0.049 \\
\hline 30 day mortality & $1(2.0 \%)$ & $3(2.5 \%)$ & 0.847 & $1(2.0 \%)$ & $1(2.0 \%)$ & 1.000 \\
\hline
\end{tabular}

$(\mathrm{p}=0.416), \mathrm{pT}$ stage $(\mathrm{p}=0.301), \mathrm{pN}$ stage $(0.639)$, pM stage $(\mathrm{p}=1.000)$, patients who had vascular invasion $[15(30.6 \%)$ vs. $18(36.7 \%), \mathrm{p}=0.521]$, patients who received adjuvant chemotherapy [26 (53.1\%) vs. $25(51.0 \%), \mathrm{p}=0.686$ ], total hospital stay (27.2 days vs. $24.1, \mathrm{p}=0.321)$ and 30 day mortality [1 (2.0\%) vs. $1(2.0 \%), \mathrm{p}=1.000]$, did not differ between treatment groups. The eight patients with pM1 disease in the BTS group included four patients with peritoneal metastasis, two with lung metastasis, one with liver metastasis and one with both liver and lung metastasis. The eight patients with pM1 disease in the ES group after matching incuded four patients with peritoneal metastases, two with lung metastasis, one with liver metastasis and one with brain metastasis.

\section{Long-term outcomes}

The mean follow-up period was $31.7 \pm 3.06$ months in the BTS group and $31.5 \pm 3.32$ months in the ES group $(\mathrm{p}=0.970)$ (Tables 3 and 4$)$. In the PSM-matched population, overall survival was significantly less favorable for patients with stent insertion as indicated by 3-year OS $(53.0 \%$ in the BTS group and $77.2 \%$ in the ES group, $\mathrm{p}=0.039)$ and 5 -year OS $(30.6 \%$ in the BTS group and 
Table 3 Long-term outcomes in PSM-matched patients

\begin{tabular}{|c|c|c|c|}
\hline & BTS $(n=49)$ & $\mathrm{ES}(\mathrm{n}=49)$ & $P$ \\
\hline Mean follow-up period (mo) & $31.7 \pm 3.06$ & $31.5 \pm 3.32$ & 0.970 \\
\hline \multicolumn{4}{|l|}{ Overall survival (\%) } \\
\hline At $1 \mathrm{y}$ & $93.8 \pm 3.4$ & $89.6 \pm 4.4$ & 0.450 \\
\hline At $3 y$ & $53.0 \pm 8.1$ & $77.2 \pm 7.0$ & 0.039 \\
\hline At $5 y$ & $30.6 \pm 8.4$ & $55.0 \pm 12.0$ & 0.025 \\
\hline Recurrence & $25(51.0 \%)$ & $13(26.5 \%)$ & 0.013 \\
\hline Regional recurrence & $10(20.4 \%)$ & $4(8.2 \%)$ & 0.083 \\
\hline Distant metastasis & $15(30.6 \%)$ & $9(18.4 \%)$ & 0.159 \\
\hline
\end{tabular}

Table 4 Multivariable analysis of known risk factors for overall survival

\begin{tabular}{lcc}
\hline & Hazard ratio & $P$ \\
\hline BTS and ES patients (After PSM analysis) & & \\
ASA score & $1.271(0.827-1.953)$ & 0.274 \\
Stenting & $2.309(1.052-5.066)$ & 0.037 \\
Stoma creation & $1.61(0.764-3.391)$ & 0.210 \\
Surgical AEs & $1.394(1.053-1.845)$ & 0.020 \\
PTNM stage & $1.706(1.116-2.607)$ & 0.014 \\
Perineural invasion & $0.82(0.371-1.809)$ & 0.622 \\
BTS patients only & & \\
Time from stenting to resection & $1.003(0.997,1.01)$ & 0.315 \\
Surgical AEs & $1.678(1.126,2.501)$ & 0.011 \\
PTNM stage & $2.125(1.177,3.836)$ & 0.012 \\
Perineural invasion & $1.158(0.42,3.195)$ & 0.776 \\
Adjuvant therapy & $1.194(0.447,3.191)$ & 0.723 \\
\hline
\end{tabular}

$55.0 \%$ in the ES group, $\mathrm{p}=0.025)$. The median overall survival was 41 months in the BTS group and 65 months in the $\operatorname{ES} \operatorname{group}(\mathrm{p}=0.041)$ (Fig. 2). The total recurrence rate was significantly increased in the BTS group [25 $(51.0 \%)$ vs. 13 (26.5\%), $\mathrm{p}=0.013$ ]. However, no significant differences were noted between the two groups in terms of regional recurrence $[10(20.4 \%)$ vs. 4 (8.2\%), $\mathrm{p}=0.083]$ and distant metastasis $[15(30.6 \%)$ vs. 9 (18.4\%), $\mathrm{p}=0.159]$.

In multivariate Cox regression analysis, stenting (hazard ratio $(H R)=2.309(1.052-5.066), p=0.037)$, surgical AEs $[H R=1.394 \quad(1.053-1.845), p=0.020]$ and pTNM stage $[H R=1.706(1.116-2.607), p=0.014]$ were positively correlated with overall survival in matched patients. Other factors, including ASA score, stoma creation and perineural invasion, showed significant differences in univariate analysis, but no significant differences in multivariate analysis. In the BTS group only, surgical AEs $(\mathrm{p}=0.011)$ and $\mathrm{pTNM}$ stage $(\mathrm{p}=0.012)$ were associated with the overall survival estimate. Other factors that are known for predictors of postoperative survival, including age, time from stenting to resection, perineural invasion and adjuvant therapy, were also included in the analysis but showed no significance.

\section{Discussion}

This study is a multicenter trial that analyzed retrospective data from three hospitals with considerable followup periods where both BTS and ES were available. The results of this observational study suggest that SEMS placement as BTS in patients with AMLCO was associated with fewer primary stoma creations, higher total inhospital costs and more perineural invasion. Patients in the BTS group had a higher recurrence rate and poorer 3-year and 5-year overall survival, which were closely correlated with surgical adverse effects and pTNM stage.

Successful placement of the stent relies on the severity of colonic obstruction and expertise of the endoscopist. The technical (89.8\%) and clinical success $(85.7 \%)$ rates in this study were similar to those in previous studies $(84.2-100 \%$ and $78.9-100 \%$, respectively) [18]. Established short-term advantages of bridged surgery include less temporary and permanent stoma creation as analyzed in many meta-analyses [18, 19]. Our study confirmed that BTS significantly increased the use of laparoscopy and decreased stoma creation.

However, recent studies have failed to show beneficial effects of stenting as BTS over emergency surgery, due to uncertainty of its impact on long-term oncological outcomes [20, 21]. This originates from concerns about tumor manipulation during stent insertion, guidewire perforations during stent placement [22], stent deployment force and eventual microperforations at the proximal and distal ends of the stent [23], which may induce tumor cell dissemination locally but also in the bloodstream [13]. In our study, we found that patients with BTS had a higher risk of perineural invasion, similar to Kim's findings [24]. In a multivariate analysis by Leibig et al. [25], perineural invasion was thought to be an independent prognostic factor of oncological outcomes in colorectal cancer. In our analysis, perineural invasion was significantly associated with the overall survival of propensity score-matched patients by univariate survival analysis (data not shown). However, the correlation was not significant in multivariate analysis. Long-term largescale studies are needed to better investigate the correlation of perineural invasion and oncological outcomes. Stent insertion was associated with more total recurrence in this study, although the difference was not significant in regional or distant recurrence alone. Similar to the findings in our study, a recent meta-analysis [26] of 7 randomized controlled trials demonstrated that BTS significantly increased the risk of recurrence, especially distant recurrence. 


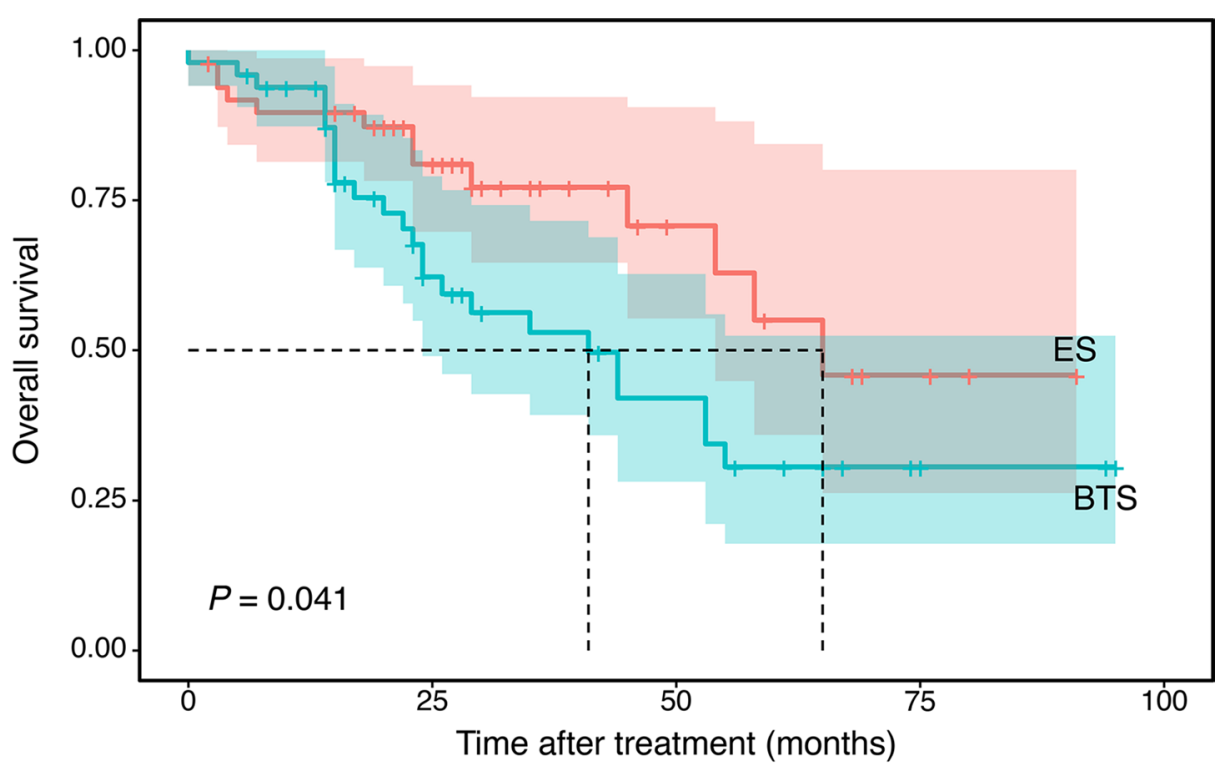

No. at risk

$\begin{array}{lllcll}\text { BTS } & 49 & 26 & 9 & 3 & 0 \\ \text { ES } & 49 & 22 & 11 & 3 & 0\end{array}$

Fig. 2 Survival curves for bridge to surgery (BTS) vs. emergency surgery (ES) (propensity score-matched patients)

To date, very few studies have reported on long-term survival after SEMS placement as a BTS due to a scarcity of clinical data and the lack of comparable studies. Femke et al. [19] found that SEMS placement as BTS did not influence 3 and 5 year overall survival in a meta-analysis. This finding is similar to Sun's findings [12], which suggest colonic stenting did not affect 5 and 10 year survival; however, the study population is relatively small and an accurate conclusion cannot be drawn. However, in Kim's study [27], SEMS placement negatively affected 5 year overall survival and disease-free survival (DFS) in stage II and III CRCs (5-year OS: 44\% after SEMS versus $87 \%$ after elective surgery for nonobstructing CRC). Sabbagh et al. [21] also found that 5 year overall survival was significantly lower in the BTS group, whereas 5 year cancerspecific mortality was significantly higher (48 vs. $21 \%$, $\mathrm{p}=0.02$ ). However, no significant differences in terms of 5 year DFS were noted. In our study, we found that 3 and 5 year overall survival were significantly lower in patients who underwent SEMS as BTS than in those who underwent ES.

Colonic stent insertion also affects patient survival in multiple aspects. Avlund et al. performed a 10-year follow-up study and concluded an association between SEMS-related perforations and decreased survival [28]. The interval from SEMS to resection surgery was thought to delay the surgery and increase the rate of recurrence and survival in the study by Broholm [20]; however, further larger studies are needed to confirm the results. Postoperative adverse effects, especially infectious complications, were associated with poorer survival in patients after colorectal cancer resection [29]. SEMS insertion was also reported to be associated with increased perineural invasion [30], which is a known prognostic factor in CRCs and correlates with the findings in our study. Many clinical factors could influence the prognosis of obstructing CRCs and overall survival. An analysis by Rodrigues et al. suggests that pTMN stage IV, number of lymph nodes harvested, adjuvant therapy and surgery-related complications could influence overall survival [2]. In our study, stenting along with surgical adverse effects and pTNM stage were associated with overall survival by multivariate analysis of propensity score-matched patients.

The present study had several limitations. First, its retrospective nature may introduce selection bias and affect the results. Second, because the population after propensity score matching was relatively small, the analysis of some variables showed a wide range. The effect of SEMSs as BTSs should be cautiously interpreted. Third, although the medical records were carefully reviewed and followup studies were thoroughly performed the causes of death were difficult to confirm in some cases, and disease-free survival was lacking. The strengths of our studies are the homogeneity between groups, due to the use of PSM analysis and the long follow-up period. 


\section{Conclusions}

SEMS placement was associated with high technical and clinical success, similar to ES, as demonstrated by the higher primary anastomosis rate and lower stoma rates, with its possible positive effects on quality of life. However, SEMS placement as a BTS leads to more perineural invasion, higher recurrence rate and worse long-term overall survival compared to ES. These results suggest that SEMS placement should not be routinely performed in patients with potentially cured AMLCOs.

\begin{abstract}
Abbreviations
BTS: Bridge to surgery; SEMS: Self-expanding metal stent; ES: Emergency surgery; AMLCO: Acute malignant left-sided colonic obstruction; PSM: Propensity score matching; AE: Adverse effect; CRC: Colorectal cancer; OS: Overall survival; RCT: Randomized controlled trial; ASA: American Society of Anesthesiology; DFS: Disease-free survival.
\end{abstract}

\section{Acknowledgements}

We acknowledge the support from Department of General Surgery and Endoscopy Center in patient diagnosis and treatment.

\section{Authors' contributions}

Conception and design: BG and QH; Acquisition of data: YC, QC, ZN, FW, CH, JZ, SZ; Analysis and interpretation of data: YC, QC, ZN and QH; Writing, review and revision of the manuscript: $\mathrm{YC}, \mathrm{QC}$ and $\mathrm{QH}$; Funding: $\mathrm{QH}$; All authors read and approved the manuscript.

\section{Funding}

The study design, data collection and manuscript writing of the project are supported by the Karamay Municipal Science and Technology Foundation (JK2017-3)(Qi Huang). The data analysis, data interpretation and manuscript editing of the project are supported by The Research and Development Fund Project of Tongji Hospital (ITJ(ZD)1804)(Qi Huang).

\section{Availability of data and materials}

The datasets used and analyzed during the current study are available from the corresponding author on reasonable request.

\section{Declarations}

\section{Ethics approval and consent to participate}

The current study was approved by Tongji University Affiliated Shanghai Tongji Hospital.

\section{Consent for publication}

Not applicable.

\section{Competing interests}

The authors declare that they have no competing interests.

\section{Author details \\ ${ }^{1}$ Department of General Surgery, Tongji Hospital, Tongji University School of Medicine, 389 Xincun Road, 200065 Shanghai, China. ${ }^{2}$ Department of Colo- rectal Surgery, Ningbo First Hospital, 315010 Ningbo, China. ${ }^{3}$ Department of General Surgery, Shanghai Tenth People's Hospital, Tongji University School of Medicine, 200072 Shanghai, China. ${ }^{4}$ Department of General Surgery, Hwa Mei Hospital, University of Chinese Academy of Sciences, 315010 Ningbo, China.}

Received: 3 November 2020 Accepted: 10 March 2021

Published online: 20 March 2021

\section{References}

1. Dekker E, Tanis PJ, Vleugels JLA, Kasi PM, Wallace MB. Colorectal cancer. Lancet. 2019:394(10207):1467-80.

2. Rodrigues-Pinto E, Morais R, Coelho C, Pereira P, Repici A, Macedo G. Bridge-to-surgery versus emergency surgery in the management of left-sided acute malignant colorectal obstruction - Efficacy, safety and long-term outcomes. Dig Liver Dis. 2019;51(3):364-72.

3. Cheynel N, Cortet M, Lepage C, Benoit L, Faivre J, Bouvier AM. Trends in frequency and management of obstructing colorectal cancers in a welldefined population. Dis Colon Rectum. 2007;50(10):1568-75.

4. Tanis PJ, Paulino Pereira NR, van Hooft JE, Consten EC, Bemelman WA Resection of obstructive left-sided colon cancer at a national level: a prospective analysis of short-term outcomes in 1,816 patients. Dig Surg 2015;32(5):317-24

5. Occhionorelli S, Tartarini D, Cappellari L, Stano R, Vasquez G. Colonic stent placement as a bridge to surgery in patients with left-sided malignant large bowel obstruction. An observational study. G Chir. 2014;35(11-12):283-9.

6. Shimura T, Joh T. Evidence-based clinical management of acute malignant colorectal obstruction. J Clin Gastroenterol. 2016;50(4):273-85.

7. Deans GT, Krukowski ZH, Irwin ST. Malignant obstruction of the left colon. Br J Surg. 1994;81(9):1270-6.

8. Arezzo A, Passera R, Lo Secco G, Verra M, Bonino MA, Targarona E, Morino M. Stent as bridge to surgery for left-sided malignant colonic obstruction reduces adverse events and stoma rate compared with emergency surgery: results of a systematic review and meta-analysis of randomized controlled trials. Gastrointest Endosc. 2017:86(3):416-26.

9. Allievi N, Ceresoli M, Fugazzola P, Montori G, Coccolini F, Ansaloni L. Endoscopic stenting as bridge to surgery versus emergency resection for left-sided malignant colorectal obstruction: an updated meta-analysis. Int J Surg Oncol. 2017;2017:2863272.

10. Tan CJ, Dasari BV, Gardiner K. Systematic review and meta-analysis of randomized clinical trials of self-expanding metallic stents as a bridge to surgery versus emergency surgery for malignant left-sided large bowel obstruction. Br J Surg. 2012;99(4):469-76.

11. Saito S, Yoshida S, Isayama H, Matsuzawa T, Kuwai T, Maetani I, Shimada M, Yamada T, Tomita M, Koizumi K, et al. A prospective multicenter study on self-expandable metallic stents as a bridge to surgery for malignant colorectal obstruction in Japan: efficacy and safety in 312 patients. Surg Endosc. 2016:30(9):3976-86.

12. Park SJ, Lee KY, Kwon SH, Lee SH. Stenting as a bridge to surgery for obstructive colon cancer: does it have surgical merit or oncologic demerit? Ann Surg Oncol. 2016;23(3):842-8.

13. Maruthachalam K, Lash GE, Shenton BK, Horgan AF. Tumour cell dissemination following endoscopic stent insertion. Br J Surg. 2007;94(9):1151-4.

14. Jung WB, Shin JY, Park JK. Comparison of short-term outcome between diverting colostomy and colonic stent as a bridge to surgery for left colonic malignant obstruction. Med (Baltim). 2020;99(14):e19557.

15. Baron TH, Harewood GC. Enteral self-expandable stents. Gastrointest Endosc. 2003;58(3):421-33.

16. Dindo D, Demartines N, Clavien PA. Classification of surgical complications: a new proposal with evaluation in a cohort of 6336 patients and results of a survey. Ann Surg. 2004;240(2):205-13.

17. Le Borgne F, Giraudeau B, Querard AH, Giral M, Foucher Y. Comparisons of the performance of different statistical tests for time-to-event analysis with confounding factors: practical illustrations in kidney transplantation. Stat Med. 2016;35(7):1103-16.

18. Atukorale YN, Church JL, Hoggan BL, Lambert RS, Gurgacz SL, Goodall S, Maddern GJ. Self-expanding metallic stents for the management of emergency malignant large bowel obstruction: a systematic review. J Gastrointest Surg. 2016;20(2):455-62.

19. Amelung FJ, BurghgraefTA, Tanis PJ, van Hooft JE, Ter Borg F, Siersema PD, Bemelman WA, Consten ECJ. Critical appraisal of oncological safety of stent as bridge to surgery in left-sided obstructing colon cancer; a systematic review and meta-analysis. Crit Rev Oncol Hematol. 2018;131:66-75.

20. Broholm M, Kobborg M, Frostberg E, Jeppesen M, Gogenur I. Delay of surgery after stent placement for resectable malignant colorectal obstruction is associated with higher risk of recurrence. Int J Colorectal Dis. 2017;32(4):513-6. 
21. Sabbagh C, Browet F, Diouf M, Cosse C, Brehant O, Bartoli E, Mauvais F, Chauffert B, Dupas JL, Nguyen-Khac E, et al. Is stenting as "a bridge to surgery" an oncologically safe strategy for the management of acute, left-sided, malignant, colonic obstruction? A comparative study with a propensity score analysis. Ann Surg. 2013;258(1):107-15.

22. Lee YJ, Yoon JY, Park JJ, Park SJ, Kim JH, Youn YH, Kim TI, Park H, Kim WH, Cheon JH. Clinical outcomes and factors related to colonic perforations in patients receiving self-expandable metal stent insertion for malignant colorectal obstruction. Gastrointest Endosc. 2018:87(6):1548-57.e1541.

23. Takahashi G, Yamada T, Iwai T, Takeda K, Koizumi M, Shinji S, Uchida E. Oncological assessment of stent placement for obstructive colorectal cancer from circulating cell-free DNA and circulating tumor DNA dynamics. Ann Surg Oncol. 2018;25(3):737-44.

24. Kim HJ, Choi GS, Park JS, Park SY, Jun SH. Higher rate of perineural invasion in stent-laparoscopic approach in comparison to emergent open resection for obstructing left-sided colon cancer. Int J Colorectal Dis. 2013;28(3):407-14.

25. Liebig C, Ayala G, Wilks J, Verstovsek G, Liu H, Agarwal N, Berger DH, Albo $D$. Perineural invasion is an independent predictor of outcome in colorectal cancer. J Clin Oncol. 2009;27(31):5131-7.

26. Foo CC, Poon SHT, Chiu RHY, Lam WY, Cheung LC, Law WL. Is bridge to surgery stenting a safe alternative to emergency surgery in malignant colonic obstruction: a meta-analysis of randomized control trials. Surg Endosc. 2019;33(1):293-302.
27. Kim JS, Hur H, Min BS, Sohn SK, Cho CH, Kim NK. Oncologic outcomes of self-expanding metallic stent insertion as a bridge to surgery in the management of left-sided colon cancer obstruction: comparison with nonobstructing elective surgery. World J Surg. 2009;33(6):1281-6.

28. Avlund TH, Erichsen R, Ravn S, Ciplys Z, Andersen JC, Laurberg S, Iversen $\mathrm{LH}$. The prognostic impact of bowel perforation following self-expanding metal stent as a bridge to surgery in colorectal cancer obstruction. Surg Endosc. 2018;32(1):328-36.

29. Artinyan A, Orcutt ST, Anaya DA, Richardson P, Chen GJ, Berger DH. Infectious postoperative complications decrease long-term survival in patients undergoing curative surgery for colorectal cancer: a study of 12,075 patients. Ann Surg. 2015;261(3):497-505.

30. Sabbagh C, Chatelain D, Trouillet N, Mauvais F, Bendjaballah S, Browet F, Regimbeau JM. Does use of a metallic colon stent as a bridge to surgery modify the pathology data in patients with colonic obstruction? A casematched study. Surg Endosc. 2013;27(10):3622-31.

\section{Publisher's note}

Springer Nature remains neutral with regard to jurisdictional claims in published maps and institutional affiliations.
Ready to submit your research? Choose BMC and benefit from:

- fast, convenient online submission

- thorough peer review by experienced researchers in your field

- rapid publication on acceptance

- support for research data, including large and complex data types

- gold Open Access which fosters wider collaboration and increased citations

- maximum visibility for your research: over $100 \mathrm{M}$ website views per year

At BMC, research is always in progress.

Learn more biomedcentral.com/submissions 